Bianca Gonzalez Martins

(D) https://orcid org/0000-0003-1220-103X

Júlia Valério Barra'

(- https://orcid.org/0000-0002-8553-9691

Wanderson Roberto da Silva

() https://orcid.org/0000-0001-8897-8772

João Marôco

(1) https://orcid.org/0000-0001-9214-5378

Juliana Alvares Duarte Bonini

Campos $^{1}$

근tps://orcid.org/0000-0001-7123-5585

\section{Body Appearance (Dis)satisfaction Scale applied to Brazilian university students}

\author{
Escala de (In)Satisfação com a Aparência Corporal aplicada a universitários brasileiros
}

DOl: $10.1590 / 0047-2085000000325$

\section{ABSTRACT}

Objective: This study aimed to estimate the psychometric properties of the Body Area Scale (BAS) applied to a sample of Brazilian university students to support the validity and reliability of the obtained data. Methods: We performed confirmatory factor analysis (CFA) using the Comparative Fit index (CFI), Tucker-Lewis index (TLI), and Root Mean Square Error of Approximation (RMSEA). We calculated the average variance extracted (AVE), composite reliability (CR), and ordinal alpha coefficient (a). All estimates were calculated separately for women and men. A thousand students participated (women $=64.0 \%$, mean $[M]$ age $=20.92$, standard deviation $[S D]=2.40$ years; body mass index (BMI) $M=23.24, S D=$ $3.97 \mathrm{~kg} / \mathrm{m}^{2}$ ). Results: Considering the CFA results, the original unifactorial model (24 items) did not fit data for women and men. Instead, the two-factorial model with 19 items had adequate fit for male and female samples (CFI = 0.922-0.958; $\mathrm{TLI}=0.912-0.952 ; \mathrm{RMSEA}=0.090-0.096)$, as well as good convergent validity (AVE $=0.536-0.668)$ and reliability $(C R=0.920-0.952 ; a=0.916-0.948)$. Once BAS was proposed to evaluate satisfaction/dissatisfaction with one's own body, and considering the reformulation of the factorial model, we proposed a new name for the instrument: Body Appearance (Dis)Satisfaction Scale (BAS-R). Conclusion: Professionals can now include the BAS-R in future protocols to evaluate satisfaction/dissatisfaction with the body in Brazilian students.

\section{KEYWORDS}

Body image, satisfaction, dissatisfaction, students, factorial analysis.

\section{RESUMO}

Objetivo: Estimar as propriedades psicométricas de uma escala desenvolvida para avaliar a satisfação/ insatisfação com o corpo quando aplicada em uma amostra de estudantes universitários brasileiros. Métodos: A validade de construto da escala foi estimada a partir de análise fatorial confirmatória. Os índices Comparative Fit Index (CFI), Tucker-Lewis Index (TLI) e Root Mean Square Error of Approximation (RMSEA) foram utilizados. A variância extraída média (VEM), a confiabilidade composta (CC) e o coeficiente alfa ordinal também foram calculados. Todas as estimativas foram calculadas para as amostras feminina e masculina. Participaram 1.000 estudantes (mulheres $=64,0 \%$ ). A média de idade para a amostra total foi de 20,92 [desvio-padrão (DP) =2,40] anos e o índice de massa corporal (IMC) médio foi de $23,24(\mathrm{DP}=3,97) \mathrm{kg} / \mathrm{m}^{2}$. Resultados: A estrutura unifatorial original da escala composta por 24 itens não apresentou ajustamento adequado. Após modificações, o modelo bifatorial composto por 19 itens apresentou ajustamento adequado às amostras masculina e feminina ( $C F I=0,922-0,958 ; \mathrm{TLI}=$ 0,912-0,952; RMSEA =0,090-0,096), bem como adequada validade convergente (VEM=0,536-0,668) e confiabilidade ( $C C=0,920-0,952 ; a=0,916-0,948)$. Com a reestruturação do modelo fatorial, a denominação "Escala de (In)satisfação com a Aparência Corporal" foi apresentada e a sigla BAS-R foi adotada. Conclusão: A partir desses indicadores, pesquisadores e clínicos poderão utilizar essa escala para levantar informações sobre a satisfação/insatisfação com o corpo em universitários.

PALAVRAS-CHAVE

Imagem corporal, satisfação, insatisfação, estudantes, análise fatorial.
Received in: Nov/23/2020. Approved in: Feb/3/2021

1 Universidade Estadual Paulista (Unesp), School of Pharmaceutical Sciences of Araraquara, Department of Biological Sciences, Araraquara, SP, Brazil. 2 William James Center for Research (WJCR), University Institute of Psychological, Social and Life Sciences, Lisboa, Portugal.

Address for correspondence: Juliana Alvares Duarte Bonini Campos. Universidade Estadual Paulista, Faculdade de Ciências Farmacêuticas de Araraquara, Departamento de Ciências Biológicas. Rodovia Araraquara-Jaú, km 01 - 14800-901 - Araraquara, SP, Brazil. Telephone: +55 (16) 3301-6935. E-mail: juliana.campos@unesp.br 


\section{INTRODUCTION}

Satisfaction/dissatisfaction with one's overall body appearance involves positive or negative self-attributions in the perception of the real versus ideal body image'. The satisfaction/dissatisfaction concept contributes to the evaluation of body image.

Body dissatisfaction is one characteristic that can predispose individuals to developing eating disorders or body dysmorphic disorder ${ }^{2,3}$. Dissatisfaction mainly occurs because of an internalized ideal body image that has been established culturally as necessary to self-perceive body adequacy. The need to achieve the ideal body has been noted by other researchers in this area'; however, as this ideal is often unattainable, this standard can generate dissatisfaction ${ }^{5}$. Body perception dissatisfaction is common among vulnerable individuals (80\%), such as young people undergoing constant physical and psychological changes ${ }^{5,6}$. Furthermore, some studies $5,7,8$ have suggested that body satisfaction and dissatisfaction can differ between females and males.

For the evaluation of satisfaction/dissatisfaction with general body appearance, it is common to administer selfrating scales containing body figures, or psychometric scales $^{5}$. Among these, we can highlight one presented by Rosen and Ross ${ }^{9}$ and adopted by Lerner et al. ${ }^{10}$. In 2009, Conti et al. ${ }^{6}$ named this scale the Body Area Scale (BAS) and presented the BAS Portuguese version. It was developed as a 24-item instrument that evaluates individuals' satisfaction/ dissatisfaction with weight and specific parts of their body (e.g., eyes, hips, and arms). The BAS proposal corroborates with the "beauty standards" presented by Tiggermann", which refer not only to weight, but also to eyes, height, legs, and skin color. Thus, despite the existence of other instruments evaluating body satisfaction, most are focused on weight and body shape ${ }^{12}$, while the BAS encompasses specific body areas that can be relevant for the assessment of body satisfaction/dissatisfaction.

Despite the availability of the BAS in Portuguese, its psychometric properties have not been fully presented in the literature. Conti et al. ${ }^{6}$ reported adequate internal consistency of the BAS for a sample of Brazilian adolescents; however, the authors did not perform an analysis to verify the factorial validity. It should be highlighted that evaluating psychometric properties, including validity estimates, is important ${ }^{13}$.

Regarding the BAS factorial model, the original proposal is unifactorial, that is, considering all body areas simultaneously ${ }^{10}$ to compose the concept of general satisfaction/dissatisfaction. However, it is noted that the content of the items considers body parts and face components separately (e.g., waist, arms, shoulder width versus eyes, mouth, and nose). Cash and Smolak ${ }^{5}$ reported that satisfaction with appearance can be related to different characteristics (e.g., arms, legs, face, and hair). This difference can occur in the context of social interaction, visual attention ${ }^{14}$, and body exposure; thus, the evaluation of face and body parts separately may be relevant to understanding one's satisfaction/dissatisfaction. In this way, as an alternative to the unifactorial model, a two-factor model could also be investigated.

University students have been highlighted as vulnerable populations for negative body image ${ }^{15}$. Laus et al. ${ }^{12}$ reported that most instruments used to assess body image in the Brazilian context were evaluated in samples of university students. BAS was evaluated only in adolescent ${ }^{6,12}$. It should be mentioned that the transition between high school and university is generally marked by new challenges as the academic demands and socialization needs. At this stage, individuals may have inappropriate eating behaviors (e.g., fast-food overconsumption and excessive alcohol intake) ${ }^{15}$ that can influence body image. This fact associated with the exposition of an individual to "beauty standards"11 may trigger feelings of inadequacy, possibly resulting in body dissatisfaction.

Thus, the aim of this study was to investigate the psychometric properties of the BAS Portuguese version when applied to a sample of Brazilian university students.

\section{METHODS}

\section{Study design}

This was a cross-sectional observational study designed with a non-probabilistic convenience sample. Initially, we calculated the minimum sample size under the assumption of 5-10 individuals per parameter ${ }^{16}$ of the BAS original model ${ }^{10}$. As the scale applied was originally developed as a unifactorial model composed of 24 items (48 parameters $=24$ items +24 errors), the minimum sample size was 240-480 individuals. Accounting for a dropout rate of $20 \%$, we corrected the minimum sample size for participant recruitment to be 300-600 participants.

\section{Participants}

We invited students from a public university (São Paulo, Brazil) to participate in the study. Those who completed all scale items and signed the informed consent form were 18-30 years old. Participants provided data on sex, age, major area of the course (human sciences: public administration, economic sciences, social sciences, letters, education; exact sciences: bioprocess engineering and biotechnology; health/biological sciences: pharmacy), year of study, weight, and height. In addition, we estimated the participants' economic level using the Brazilian Economic 
Classification Criteria ${ }^{17}$. Self-reported measures of weight and height were used to calculate body mass index (BMI) and to classify anthropometric nutritional status ${ }^{18}$. A total of 1,159 students participated in the study, and 159 (13.7\%) were excluded because they did not complete all the items of the instrument, leaving a final participant total of 1,000 students. The students completed the questionnaire during class hours with the teachers' authorization to collect the data. The researchers emphasized in class that participation was voluntary, and we included only those who gave informed consent. The study protocol was approved by the Human Research Ethics Committee of the School of Pharmaceutical Sciences of São Paulo State University (CAAE: 63553516.4.0000.5426).

\section{Measure}

We estimated the students' satisfaction and dissatisfaction with the general appearance of their body using the Portuguese version of the BAS ${ }^{6}$. The BAS was originally proposed in English as a unifactorial model with 24 items related to specific parts of the body and the body's general appearance $^{10}$. The instrument was suited for both men and women $^{10}$. A 5-point Likert-type scale was used to respond to the items ( 1 = very satisfied, 5 = very dissatisfied). Conti et al. ${ }^{6}$ found Cronbach's alpha $(a)=0.88$ and 0.90 for female and male samples, respectively. In addition, girls completed BAS in 2.1 (standard deviation [SD] =0.8) minutes and boys in 2.0 $(S D=0.8)$ minutes.

\section{Psychometric analysis}

The psychometric sensitivity of items was investigated using summary measures as mean, median, and standard deviation, and measures of form of distribution as skewness and kurtosis. Adequacy of psychometric sensitivity was considered when absolute values of skewness were $<3$ and kurtosis $<7^{13}$. The samples of women and men were evaluated separately.

The original psychometric properties of the scale were based on Lerner et al.'s ${ }^{10}$ unifactorial model. We conducted confirmatory factor analysis (CFA) with the robust weighted least squares estimation method adjusted for mean and variance and employed the Comparative Fit index (CFI), the Tucker-Lewis index (TLI), and the Root Mean Square Error of Approximation (RMSEA) with a 90\% confidence interval ( $90 \% \mathrm{Cl}$ ). The fit of the model to the data was considered acceptable when factor loadings $(\lambda)$ were $\geq 0.50, \mathrm{CFI}$ and $T L I \geq 0.90$, and RMSEA $\leq 0.10^{13}$. For model fit, we considered the modification indices ( $\mathrm{MI} \geq 11$ ) calculated from Lagrange multipliers ${ }^{13}$. As the unifactorial model did not fit the data, we tested an alternative model (with two factors) based on theoretical associations between the items that could compose appearance satisfaction ${ }^{5}$. In this stage, the items that presented very high $\mathrm{MI}$ (>250) with other items and/or factors were deleted stepwise (i.e., from highest to lowest). All analyses were performed separately for women and men.

We evaluated convergent validity via the average variance extracted (AVE), and values $>0.50$ were assumed to denote adequate convergent validity ${ }^{19}$. Moreover, the discriminant validity was also investigated. Discriminant validity was adequate when the AVE values of both factors were greater than the square of the correlation between these factors ${ }^{19}$.

We evaluated reliability via composite reliability (CR) according to the proposal of Fornell and Larcker $^{19}$ and the ordinal alpha coefficient (a) according to the proposal of Gadermann, Guhn, and Zumbo ${ }^{20}$. Adequate reliability was assumed at CR and $a \geq 0.70$.

The IBM SPSS Statistics v.22 (IBM Corp., Armonk, NY, USA), MPLUS (v. 7.2), and R (v. 3.6.2) were used for analyses.

\section{RESULTS}

Among the students, 64\% were women. The mean age of the total sample was 20.92 years $(S D=2.40)$. The mean age of men was 21.09 years $(S D=2.51)$, and the mean age of women was 22.80 years $(S D=2.34)$. The mean BMI was 23.24 $\mathrm{kg} / \mathrm{m}^{2}\left(\mathrm{SD}=3.97 \mathrm{~kg} / \mathrm{m}^{2}\right)$, with men at $24.05 \mathrm{~kg} / \mathrm{m}^{2}(\mathrm{SD}=3.94)$ and women at $22.80 \mathrm{~kg} / \mathrm{m}^{2}(S D=3.93)$. Table 1 shows the participants' characteristics.

The participants predominantly studied in the field of human sciences attending the first years of their course, and they were classified in anthropometric nutritional status as normal range. Moreover, most students were at economic level B (i.e., people with average purchasing power).

The descriptive statistics of the BAS items for women and men samples are presented in Table 2. We did not find extreme violations of the normality assumption, which indicates adequate psychometric sensitivity of the items.

The unifactorial BAS did not fit the samples of (a) women: $\mathrm{n}=647, \lambda=0.56-0.82, \mathrm{CFI}=0.809, \mathrm{TLI}=0.791$, and RMSEA $=0.141(90 \% \mathrm{Cl}=0.137-0.145)$; and (b) men: $\mathrm{n}=$ $353, \lambda=0.60-0.88, \mathrm{CFI}=0.868, \mathrm{TLI}=0.855$, and RMSEA $=$ $0.136(90 \% \mathrm{Cl}=0.131-0.142)$. Discrepant values were found in the modification indices, thereby indicating a correlation between the item error values.

Considering the poor results of the unifactorial model, we tested the two-factorial model based on shared features of the items. In this way, we compiled two sets of items (Facial Appearance Dissatisfaction: items 1, 2, 6, 15, 16, 17 , 18, 19, 20, 22, and 24; Body Appearance Dissatisfaction: items 3, 4, 5, 7, 8, 9, 10, 11, 12, 13, 14, 21, and 23), and named the instrument Body Appearance (Dis)Satisfaction Scale (BAS-R). 
Table 1. Characteristics of the sample of university students

\begin{tabular}{|c|c|c|c|}
\hline \multirow{2}{*}{ Characteristic } & \multicolumn{3}{|c|}{ Sample n (\%) } \\
\hline & Men & Women & Total \\
\hline \multicolumn{4}{|l|}{ Year of the course } \\
\hline First & $97(27.6)$ & $185(28.8)$ & $282(28.4)$ \\
\hline Second & $101(28.8)$ & $196(30.5)$ & $297(29.9)$ \\
\hline Third & $74(21.1)$ & $121(18.8)$ & $195(19.6)$ \\
\hline Fourth & $60(17.1)$ & $110(17.1)$ & $170(17.1)$ \\
\hline Fifth & $19(5.4)$ & $31(4.8)$ & $50(5.0)$ \\
\hline \multicolumn{4}{|c|}{ Major area of the course } \\
\hline Health/Biological & $51(14.4)$ & $187(28.9)$ & $238(23.8)$ \\
\hline Exact & $38(10.8)$ & $56(8.7)$ & $94(9.4)$ \\
\hline Human & $264(74.8)$ & $404(62.4)$ & $668(66.8)$ \\
\hline \multicolumn{4}{|c|}{ Economic level (average household income) ${ }^{\star}$} \\
\hline$A(\$ 6,187.49)$ & $118(33.4)$ & $146(22.6)$ & $264(26.4)$ \\
\hline$B(\$ 2,048.52)$ & $182(51.6)$ & $384(59.4)$ & $566(56.6)$ \\
\hline C (\$ 585.24) & $50(14.2)$ & $115(17.7)$ & $165(16.5)$ \\
\hline D-E (\$174.29) & $3(0.8)$ & $2(0.3)$ & $5(0.5)$ \\
\hline \multicolumn{4}{|c|}{ Anthropometric nutritional status } \\
\hline Underweight & $14(4.0)$ & $67(10.4)$ & $81(8.1)$ \\
\hline Normal range & $228(64.6)$ & $419(64.7)$ & $647(64.7)$ \\
\hline Overweight & $83(23.5)$ & $125(19.3)$ & $208(20.8)$ \\
\hline Obesity & $28(7.9)$ & $36(5.6)$ & $64(6.4)$ \\
\hline
\end{tabular}

* Note. Brazilian Economic Classification Criteria 2019. Brazilian reals (BRL) were converted into American dollars (exchange rate in October $2019-1 \mathrm{BRL}=4.13$ dollars).

Table 2. Descriptive statistics of the responses given to Body Area Scale (BAS) items (Women $n=647$; Men $n=353$ )

\begin{tabular}{|c|c|c|c|c|c|c|c|}
\hline \multirow{2}{*}{ Item } & \multicolumn{7}{|c|}{ Women/Men } \\
\hline & Mean & Median & SD & Skewness & Kurtosis & Minimum & Maximum \\
\hline 1) Facial complexion & $1.66 / 1.79$ & $1.00 / 1.00$ & $1.02 / 1.12$ & $1.60 / 1.26$ & $1.99 / 0.71$ & $1 / 1$ & $5 / 5$ \\
\hline 2) Ears & $1.80 / 1.96$ & $1.00 / 1.00$ & $1.20 / 1.20$ & $1.33 / 0.95$ & $0.60 /-0.23$ & $1 / 1$ & $5 / 5$ \\
\hline 3) Chest & $2.40 / 2.61$ & $2.00 / 3.00$ & $1.29 / 1.24$ & $0.44 / 0.22$ & $-1.01 /-1.03$ & $1 / 1$ & $5 / 5$ \\
\hline 4) Profile & $2.56 / 2.45$ & $2.00 / 2.00$ & $1.24 / 1.21$ & $0.36 / 0.35$ & $-1.00 /-0.91$ & $1 / 1$ & $5 / 5$ \\
\hline 5) Weight & $3.16 / 2.78$ & $3.00 / 3.00$ & $1.39 / 1.31$ & $-0.18 / 0.14$ & $-1.32 /-1.19$ & $1 / 1$ & $5 / 5$ \\
\hline 6) Eyes & $1.63 / 1.81$ & $1.00 / 1.00$ & $1.04 / 1.11$ & 1.73/1.32 & $2.23 / 1.03$ & $1 / 1$ & $5 / 5$ \\
\hline 7) Height & $2.02 / 2.10$ & $2.00 / 2.00$ & $1.21 / 1.22$ & $0.94 / 0.85$ & $-0.29 /-0.41$ & $1 / 1$ & $5 / 5$ \\
\hline 8) Ankles & $1.92 / 2.05$ & $1.00 / 2.00$ & $1.14 / 1.14$ & $0.93 / 0.75$ & $-0.09 /-0.25$ & $1 / 1$ & $5 / 5$ \\
\hline 9) Waist & $2.73 / 2.59$ & $2.00 / 3.00$ & $1.41 / 1.29$ & $0.17 / 0.19$ & $-1.38 /-1.14$ & $1 / 1$ & $5 / 5$ \\
\hline 10) Arms & $2.85 / 2.76$ & $3.00 / 3.00$ & $1.41 / 1.16$ & $0.11 / 0.13$ & $-1.35 /-0.93$ & $1 / 1$ & $5 / 5$ \\
\hline 11) Legs & $2.81 / 2.46$ & $3.00 / 2.00$ & $1.32 / 1.18$ & $0.16 / 0.42$ & $-1.25 /-0.81$ & $1 / 1$ & $5 / 5$ \\
\hline 12) General appearance & $2.53 / 2.38$ & $2.00 / 2.00$ & $1.14 / 1.14$ & $0.51 / 0.62$ & $-0.66 /-0.47$ & $1 / 1$ & $5 / 5$ \\
\hline 13) Hips & $2.69 / 2.48$ & $2.00 / 3.00$ & $1.30 / 1.17$ & $0.21 / 0.32$ & $-1.19 /-0.68$ & $1 / 1$ & $5 / 5$ \\
\hline 14) Shoulder & $2.24 / 2.29$ & $2.00 / 2.00$ & $1.21 / 1.09$ & $0.61 / 0.52$ & $-0.62 /-0.42$ & $1 / 1$ & $5 / 5$ \\
\hline 15) Mouth & $1.75 / 1.93$ & $1.00 / 2.00$ & $1.06 / 1.07$ & $1.44 / 1.03$ & $1.39 / 0.41$ & $1 / 1$ & $5 / 5$ \\
\hline 16) Neck & $1.95 / 2.01$ & $1.00 / 2.00$ & $1.13 / 1.07$ & $0.89 / 0.76$ & $-0.20 /-0.18$ & $1 / 1$ & $5 / 5$ \\
\hline 17) Teeth & $2.24 / 2.31$ & $2.00 / 2.00$ & $1.24 / 1.19$ & $0.74 / 0.52$ & $-0.61 /-0.86$ & $1 / 1$ & $5 / 5$ \\
\hline 18) Nose & $2.46 / 2.28$ & $2.00 / 2.00$ & $1.33 / 1.16$ & $0.40 / 0.42$ & $-1.15 /-0.97$ & $1 / 1$ & $5 / 5$ \\
\hline 19) Chin & $2.12 / 2.05$ & $2.00 / 2.00$ & $1.18 / 1.10$ & $0.68 / 0.66$ & $-0.55 /-0.44$ & $1 / 1$ & $5 / 5$ \\
\hline 20) Hair texture & $1.94 / 2.14$ & $1.00 / 2.00$ & $1.22 / 1.23$ & $1.14 / 0.77$ & $0.12 /-0.53$ & $1 / 1$ & $5 / 5$ \\
\hline 21) Body built & $2.53 / 2.44$ & $2.00 / 2.00$ & $1.31 / 1.24$ & $0.40 / 0.40$ & $-1.10 /-0.95$ & $1 / 1$ & $5 / 5$ \\
\hline 22) Hair color & $1.56 / 1.74$ & $1.00 / 1.00$ & $0.95 / 1.04$ & $2.04 / 1.36$ & $4.04 / 1.20$ & $1 / 1$ & $5 / 5$ \\
\hline 23) Tights & $2.68 / 2.26$ & $2.00 / 2.00$ & $1.38 / 1.21$ & $0.30 / 0.58$ & $-1.24 /-0.70$ & $1 / 1$ & $5 / 5$ \\
\hline 24) Face & $2.23 / 2.14$ & $2.00 / 2.00$ & $1.18 / 1.09$ & $0.76 / 0.71$ & $-0.37 /-0.28$ & $1 / 1$ & $5 / 5$ \\
\hline
\end{tabular}

SD: standard deviation. 
The two-factor model of BAS did not fit adequately to the samples of (a) women: $n=647, \lambda=0.60-0.88, C F I=0.850, T L I=$ 0.835 , and RMSEA $=0.125(90 \% \mathrm{Cl}=0.121-0.129)$; and (b) men: $\mathrm{n}=353, \lambda=0.62-0.91, \mathrm{CFI}=0.905, \mathrm{TLI}=0.895$, and RMSEA $=$ $0.116(90 \% \mathrm{Cl}=0.110-0.122)$. In the modified indices, Items 5 , 7,8 , and 24 were strongly correlated with the two factors (MI $=285.54-417.49)$ and Item 11 strongly correlated with Item $23(\mathrm{Ml}=763.21)$. As these items impaired the model's fit, we excluded them, leaving a model composed of 19 items and two factors (Facial Appearance Dissatisfaction: items 1, 2, 6, $15,16,17,18,19,20$, and 22; Body Appearance Dissatisfaction: items $3,4,10,12,13,14,21$, and 23). Figure 1 shows the fit of this new model for the female and male samples.

To fit the model to the male sample, we permitted a correlation between the error values of Items 9 and 13. For the female sample, the model was adequate without any additional fit. As for the convergent validity and reliability of the fitted model, all values of AVE, CR, and a were adequate for both the female and male samples. Discriminant validity was not adequate only for the female sample.

\section{DISCUSSION}

This study presents, for the first time to the best of our knowledge, the psychometric properties of a previously used self-rating scale for the assessment of satisfaction/ dissatisfaction with body appearance in a sample of Brazilian university students. The original unifactorial model of the BAS had not been subjected to confirmatory analysis in previous studies. In the present work, this model was notadequatefor the samples. Therefore, we developed and evaluated a new model based on the theoretical associations between items. In earlier literature, we found only data on the reliability of the scale ${ }^{21}$. The reliability data were interesting but should be calculated only after assessing instrument validity ${ }^{13}$. Thus, we performed a broad evaluation of the scale's psychometric properties to help researchers in this subject area use it comfortably. We hope that our results will substantially contribute to the literature on body image by providing needed information about a good tool for evaluating satisfaction/dissatisfaction with the general appearance of the body.

The new two-factorial model for the BAS designed in this study (BAS-R) is composed of 19 items and two factors, and this structure yielded an adequate fit for both male and female samples. First, we removed Item 11 (legs), due to its high correlation with Item 23 (thighs), possibly because participants regarded both the upper (thighs) and lower (knee) parts as "legs." It will be interesting in further studies to specify exactly which body part the item refers to. We removed Items 5 (weight), 7 (height), 8 (ankle), and 24 (face) because they highly correlated with both scale factors, were not specific, and undesirably reflected both concepts simultaneously.

Regarding the scale's configurational structure (i.e., the number of items and factors), it proved similar between male and female samples, except for a correlation between Item 9

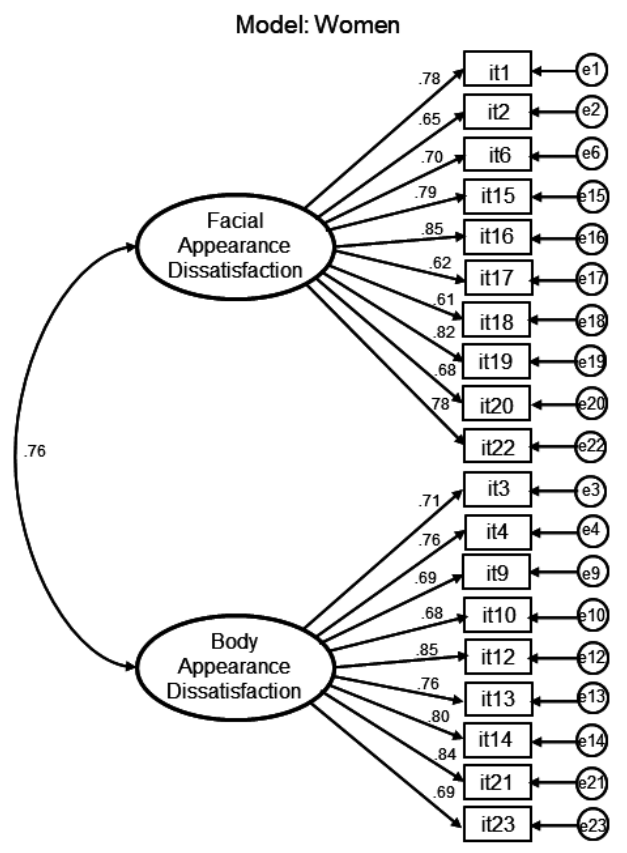

$\mathrm{CFI}=.922 ; \mathrm{TL}=.912$

RMSEA $=.096(90 \% \mathrm{Cl}=.091-.102) ; \mathrm{AVE}=.536-.578$; $\mathrm{CR}=.920-.922 ; \alpha=.916-.918$

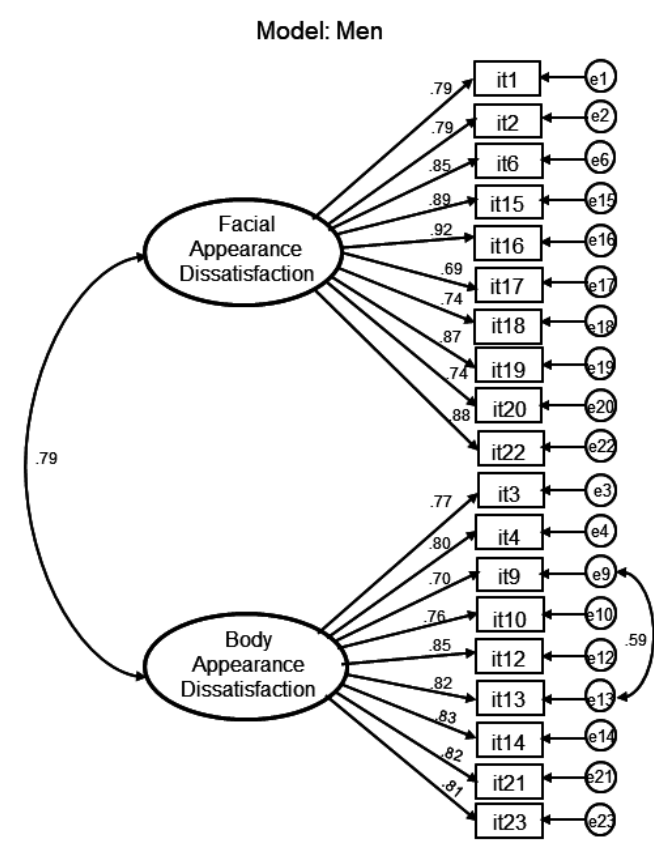

$\mathrm{CFI}=.958 ; \mathrm{TL}=.952 ;$

RMSEA $=.090(90 \% \mathrm{Cl}=.082-.098) ; \mathrm{AVE}=.660-.668$ $\mathrm{CR}=.945-.952 ; \alpha=.939-.948$

Figure 1. Psychometric estimates of the Body Appearance (Dis)Satisfaction Scale (two-factorial model) fitted for university students samples.

Note. CFI: Comparative Fit Index; TLl: Tucker-Lewis Index; RMSEA: Root Mean Square Error of Approximation, 90\%Cl: Confidence interval of 90\% of RMSEA; AVE: Average Variance Extracted; CR: Composite reliability; $\alpha=$ ordinal alpha coefficient. 
(waist) and Item 13 (hip) that was found in the male sample. This result can be ascribed to differences in body perception between men and women ${ }^{22}$. We believe that the high correlation observed between Items 9 and 13 could have occurred because the "waist" and "hip" are not generally the parts of the body that men care about most.

The comparison of our results with past literature is difficult because there are no prior data regarding the factorial validity of the scale we used. In addition, the name of the scale was altered in this study to reflect the new factorial model. In the original study, the authors ${ }^{10}$ did not propose name for the scale; they merely reported that the instrument was developed to assess characteristics of satisfaction with the body. Subsequent studies ${ }^{21,23}$ have described the scale as "Lerner's Body Image Scale" or, in a Brazilian study", the "Body Area Scale (BAS)." Discrepancies in the name of the scale interfere with its use through difficulty tracing the instrument in literature analyses. Accordingly, we propose the name "Body Appearance (Dis)Satisfaction Scale (BAS-R)" to fully consider the revised structure of the new model.

Some limitations of this study include the use of a nonprobabilistic sample, preventing broad generalization of these results to all Brazilian students or young adults. Our restrictions on the age of these participants prevent confident use or comparisons among various age groups. In addition, the size of our samples did not allow testing of the factorial invariance using independent subsamples. Thus, future studies using the BAS-R should be carried out to assess factorial invariance across men and women and independent samples to provide evidence about the external validity of the instrument. Despite these limitations, our study provides psychometric support for this means of evaluating satisfaction/dissatisfaction with one's own body appearance.

\section{CONCLUSION}

The unifactorial model of thescaleevaluated was notadequate for samples of Brazilian students. Thus, we developed a two-factorial model and re-named the instrument Body Appearance (Dis)Satisfaction Scale (BAS-R). The BAS-R now shows adequate validity and reliability among both male and female Brazilian samples, making it possible for investigators to use this tool to evaluate individuals with characteristics similar to those of the participants of this study.

\section{INDIVIDUAL CONTRIBUTIONS}

Bianca Gonzalez Martins - HAD substantially contributed to conception and design, collect, analysis and interpretation of data, writing/drafting the article and given the final approval of the version to be published.

Júlia Valério Barra - Had substantially contributed to conception and design, collect, analysis and interpretation of data, writing/drafting the article and given the final approval of the version to be published.

Wanderson Roberto da Silva - Had substantially contributed to conception and design, analysis and interpretation of data, revising the article critically for important intellectual content and given the final approval of the version to be published.

João Marôco - Had substantially contributed to conception and design, analysis and interpretation of data, revising the article critically for important intellectual content and given the final approval of the version to be published.

Juliana Alvares Duarte Bonini Campos - Had substantially contributed to conception and design, analysis and interpretation of data, revising the article critically for important intellectual content and given the final approval of the version to be published.

\section{CONFLICT OF INTERESTS}

The authors declare that there is no conflict of interests.

\section{ACKNOWLEDGEMENTS}

This study was financed in part by the Coordenação de Aperfeiçoamento de Pessoal de Nível Superior (Capes, Brazil, Finance Code 001), the São Paulo Research Foundation (Fapesp; grant \#2017/18679-0) and the National Counsel of Technological and Scientific Development (CNPq; 131073/2017-6).

\section{REFERENCES}

1. Heider N, Spruyt A, De Houwer J. Body dissatisfaction revisited: on the importance of implicit beliefs about actual and ideal body image. Psychol Belg. 2018;58(1):158-73.

2. Karazsia BT, Murnen SK, Tylka TL. Is body dissatisfaction changing across time? A crosstemporal meta-analysis. Psychol Bull. 2017;143(3):293-320

3. Smolak L, Thompson JK. Body image, eating disorders, and obesity in youth: Assessment, prevention, and treatment 2nd ed. Washington, DC: American Psychological Association; 2002.

4. Schaefer LM, Burke NL, Thompson JK. Thin-ideal internalization: How much is too much? Eat Weight Disord. 2019;24(5):933-7.

5. Cash TF, Smolak L. Body Image: Handbook of Science, Practice, and Prevention. 2nd ed. New York: The Guilford Press; 2011.

6. Conti MA, Latorre MRDO, Hearst N, Segurado A. Cross-cultural adaptation, validation and reliability of the Body Area Scale for Brazilian adolescents Cad Saúde Pública. 2009;25(10):2179-86

7. Klimek P, Murray SB, Brown T, Gonzales IV M, Blashill AJ. Thinness and muscularity internalization: Associations with disordered eating and muscle dysmorphia in men. Int J Eat Disord. 2018:51(4):352-7. 
8. Schaefer LM, Burke NL, Thompson JK, Dedrick RF, Heinberg LJ, Calogero RM, et al. Development and validation of the Sociocultural Attitudes Towards Appearance Questionnaire-4 (SATAQ-4). Psychol Assess. 2015;27(1):54-67.

9. Rosen GM, Ross A0. Relationship of body image to self-concept. J Consult Clin Psychol. 1968:32(1):100.

10. Lerner RM, Karabenick SA, Stuart JL. Relations among Physical Attractiveness, Body Attitudes, and Self-Concept in male and female college students. J Psychol. 1973;85(1):119-29.

11. Tiggermann M. Sociocultural Perspectives on Human Appearance and Body Image. In: Cash TF, Smolak L, eds. Body Image. 2nd ed. New York: The Guilford Press; 2012. p. 12-9.

12. Laus MF, Kakeshita IS, Costa TMB, Ferreira MEC, Fortes LS, Almeida SS. Body Image in Brazil: recent advances in the state of knowledge and methodological issues. Rev Saúde Pública. 2014:48(2):331-46.

13. Marôco J. Análise de equações estruturais: fundamentos teóricos, software e aplicações. $2^{2}$ ed. Pêro Pinheiro: Report Number; 2014. 389p.

14. Cerf M, Frady EP, Koch C. Faces and text attract gaze independent of the task: Experimental data and computer model. J Vision. 2009;9(10):1-15.

15. Nelson MC, Story M, Larson NI, Neumark-Sztainer D, Lytle LA. Emerging Adulthood and College-aged youth: An Overlooked Age for Weight-related Behavior Change. Obesity. 2008:16:2205-11.
16. Hair Jr JF, Black WC, Babin B, Anderson RE, Tatham RL. Multivariate data analysis. 6 ed. Upper Saddle River, NJ: Prentice Hall; 2009. 928p.

17. Associação brasileira de empresas de pesquisa (ABEP). Brazilian Economic Classification Criteria (Brazilian Criteria) 2019. Available from: http://www.abep.org/criterio-brasil. Accessed on: Nov. 2020

18. World Health Organization (WHO). Obesity: preventing and managing the global epidemic. Geneva: WHO - Technical Report Series; 2000.

19. Fornell C, Larcker DF. Evaluating structural equation models with unobservable variables and measurement error. J Marketing Res. 1981;18(1):39-50.

20. Gadermann AM, Guhn M, Zumbo BD. Estimating ordinal reliability for Likert-type and ordinal item response data: A conceptual, empirical, and practical guide. Pract Assess Res Evaluat. 2012:17(3):1-13.

21. Richards MH, Boxe AM, Petersen AC, Albretch R. Relation of weight to body image in pubertal girls and boys from two communities. Dev Psychol. 1990;26(2):313-21.

22. Schaefer LM, Harriger JA, Heinberg LJ, Soderberg T, Kevin Thompson J. Development and validation of the Sociocultural Attitudes Towards Appearance Questionnaire-4-revised (SATAQ-4R). Int J Eat Disord. 2017;50(2):104-17.

23. Rosenblum GD, Lewis M. The relations among body image, physical attractiveness, and body mass in adolescence. Child Develop. 1999;70(1):50-64. 